\title{
Desafios para a implementação da lei 10.639: apontamentos sobre possíveis impactos da reforma do ensino médio no ensino de História da África*
}

Adriano Bueno da Silva

\section{Introdução: a luta do movimento negro por um currículo antirracista}

A educação formal sempre foi observada pelo movimento negro como um lugar estratégico para o combate ao racismo, sendo o principal mecanismo através do qual nossa cultura é compartilhada entre gerações. Os debates acerca do currículo escolar sempre ocuparam espaço privilegiado na pauta da militância antirracista desde a reorganização do movimento negro nos anos finais da Ditadura Militar, cujo marco inicial é a fundação do MNU (Movimento Negro Unificado) em 1978. Durante a transição democrática, diante da janela histórica aberta pela crise do regime autoritário, o movimento negro lutou para encaixar suas pautas durante a elaboração da Constituinte de 1988:

O processo educacional respeitará todos os aspectos da cultura brasileira. É obrigatório a inclusão nos currículos escolares de I, II e III graus, do ensino da História da África e da História do Negro no Brasil. ${ }^{1}$

Uma das principais conquistas do movimento negro durante a elaboração da Constituição de 1988, o Inciso XLII do Art. 50 transformou a prática de racismo em crime inafiançável e imprescritivel sujeito à reclusão. $O$ ensino de História da África, embora tenha constado como demanda durante os debates, não foi incorporado ao texto de nossa Carta Magna².

${ }^{*}$ DOI - 10.29388/978-65-86678-09-3-0-f.27-40

${ }^{1}$ Sugestão 2.886, enviada por Carlos Alves Moura, Diretor do Centro de Estudos Afro-Brasileiros; e por Maria Luiza Junior, Coordenadora Geral da Convenção "O Negro e a Constituinte", com a subscrição das entidades que estiveram na Convenção, entre elas o MNU (Bases da Assembléia Nacional Constituinte 1987-1988);

2 (NERIS, 2018) 
Sendo assim, é importante constatar que uma das principais iniciativas pautadas pelo movimento negro e inclusa no texto constituinte visava incidir sobre o fato consumado (a discriminação enquanto prática de racismo). Uma iniciativa como a inclusão de História da África nos currículos, que teria caráter preventivo por incidir sobre a raiz da reprodução do racismo, só viria a se tornar lei mais de uma década depois.

Encerrado o processo constituinte, inicia-se imediatamente depois uma batalha no parlamento, com parlamentares - destaque para Benedita da Silva e Paulo Paim, ambos do PT - empunhando a bandeira da História da África. Finalmente, em 1999, Esther Grossi e Ben-Hur Ferreira apresentam o PL $259^{3}$, que 4 anos depois seria sancionado na forma da Lei 10.639 .

Se a Lei 10.639/2003 inaugura as mudanças na legislação educacional sob o prisma do primeiro governo de Luís Inácio Lula da Silva (PT) apenas 9 dias após a sua posse, abrindo um ciclo de avanços no campo da educação para as relações raciais que duraria 14 anos; a Lei 13.415/2017 anuncia o fim deste ciclo de mudanças no campo da educação para as relações raciais, 23 dias após a posse de Michel Temer (PMDB), inaugurando um período de retrocessos que se aprofundaria após as eleições de 2018. Este é o primeiro contraste que salta aos olhos quando buscamos observar as duas leis e o que ambas sinalizam enquanto marcadores históricos.

Um outro contraste digno de registro diz respeito ao modo como cada projeto de lei foi produzido: de um lado, um governo democraticamente eleito pelo povo brasileiro põe em pauta uma matéria que vinha sendo debatida desde o final dos anos 80 pelo movimento negro, tendo sido expressa em diversas proposições parlamentares ao longo de 4 legislaturas; de outro, um governo tampão que nasceu de um golpe apresentando via Medida Provisória uma matéria controversa que não havia sido debatida com a sociedade brasileira.

A Lei $13.415 / 2017$ não foi uma medida específica de promoção da igualdade racial como a Lei 10.639/2003. Mas em sua amplitude, a Reforma do Ensino Médio afetará a educação para as relações raciais. Nosso objetivo aqui é esboçar como e em que medida o ensino de História e Cultura Africana e Afrobrasileira poderá ser afetado.

${ }^{3}$ (CÂMARA DOS DEPUTADOS, 1999) 


\section{O Contexto da Reforma do Ensino Médio: acirramento da luta de classes}

Em 2 de dezembro de 2015, antes mesmo do término do primeiro ano do mandato da presidenta Dilma Rousseff (PT), o presidente da Câmara dos Deputados Eduardo Cunha (PMDB) aceitou a denúncia por crime de responsabilidade oferecida pelo procurador de justiça aposentado Hélio Bicudo e pelos advogados Miguel Reale Júnior e Janaina Paschoal.

Em 12 de maio de 2016, após relatório favorável na Comissão; e após votação favorável ao parecer desta Comissão nos plenários da Câmara dos Deputados e do Senado, Dilma foi afastada até conclusão do processo. Por fim, no dia 31 de agosto de 2016 a presidenta Dilma, eleita com 54.501.118 votos em 2014, teria seu mandato cassado e o presidente interino Michel Temer (PMDB) assumiria em definitivo.

Todo este processo desenrolou-se em um cenário composto por manifestações de massa que aglutinavam centenas de milhares de pessoas nas ruas do país, com a oposição tirando proveito da queda de popularidade do governo da Dilma, decorrente dos efeitos da crise econômica e de concessões austeras na condução da política econômica.

Após a sua vitória em 2014 em um processo eleitoral extremamente acirrado (51,64\% dos votos válidos), Dilma havia anunciado uma equipe econômica para seu novo governo e editado medidas provisórias ${ }^{4}$ que, na contramão de seu programa eleitoral desenvolvimentista e de ampliação de direitos sociais, apontavam para uma política econômica baseada na austeridade fiscal, com mudanças nas regras de acesso a benefícios trabalhistas como segurodesemprego, auxílio-doença, pensões e abono salarial.

A queda da presidenta Dilma, longe de resolver os impasses em questão, jogou ainda mais lenha na fogueira acesa no país, em especial pelas circunstâncias, com a perícia do Senado inocentando Dilma através de um laudo e o Ministério Público não considerando as "pedaladas" como crime. Os presidentes que antecederam Dilma também realizaram manobras fiscais que não foram consideradas crimes e a Dilma não teve seus direitos políticos cassados.

O ambiente de acirramento da luta de classes ainda persistiria pelos próximos anos em decorrência da quebra da normalidade democrática estabelecida via "impeachment" sem crime de responsabilidade e do governo ilegítimo que nasceria desta ruptura, com sua pauta não referendada pelas urnas.

\footnotetext{
${ }^{4}$ Sobre as Medidas Provisórias 664 e 665 de 30 de setembro de 2014, ver: DIEESE, 2015;
} 


\title{
A Reforma do Ensino Médio: uma medida autoritária em meio a muita confusão e pouco debate público
}

Com apenas 23 dias no poder Temer pauta a Reforma do Ensino Médio diante de um país polarizado, tendo sua legitimidade questionada pelos críticos do "impeachment" e radicalizando na implementação de políticas construídas na contra-mão das que foram defendidas no processo eleitoral. O PMDB havia formulado durante o cenário de convulsão social vigente no Brasil o programa "Ponte para o Futuro", uma espécie de plataforma eleitoral do golpe. O ambiente de polarização e elevação de ânimos estava longe de se estabilizar.

O uso do recurso de uma medida provisória para a implementação da reforma foi muito questionado. Sendo um projeto cuja implementação é de médio prazo no mínimo, haveriam outras formas de fomentar o debate público, uma vez que a MP não garantiria implementação imediata. Ao justificarem o voto contrário na Comissão Mista da MP 746, a senadora Fátima Bezerra (PT) e a deputada Maria do Rosário (PT) afirmaram:

\begin{abstract}
A Medida Provisória trata-se de um ato do Executivo com força provisória de lei (mi. 62, CF), que tem como objetivo possibilitar a adoção de medidas jurídicas em face de circunstâncias relevantes e urgentes que imponham a ação imediata do Estado, caso inexistam outros instrumentos jurídicos capazes de satisfazerem a demanda. $O$ mandamento constitucional é nítido, pressupõe a existência de circunstâncias extraordinárias para a adoção de MPs, sendo qualquer outro uso deste instrumento, inconstitucional e atentatório a separação dos Poderes. ${ }^{5}$
\end{abstract}

Em 23 setembro de 2016 o presidente em exercício Michel Temer publicou a MP $746^{6}$, a Reforma do Ensino Médio. Prevista inicialmente para estar vigente até 2 de março de 2017, após sua tramitação na Câmara Federal e no Senado, a MP 746 foi aprovada e convertida na Lei 13.415 no dia 16 de fevereiro de 2017, a toque de caixa. O caos estava instalado e a pressa em articular uma reforma tão importante via medida provisória sem nenhum debate público com a sociedade elevavam a insegurança quanto às eventuais mudanças na

\footnotetext{
${ }^{5}$ Ver MP 746;

${ }^{6}$ Medida Provisória 746, que instituiu a Política de Fomento à Implementação de Escolas de Ensino Médio em Tempo Integral, alterou a Lei no 9.394, de 20 de dezembro de 1996, que estabelece as diretrizes e bases da educação nacional, e a Lei no 11.494 de 20 de junho 2007, que regulamenta o Fundo de Manutenção e Desenvolvimento da Educação Básica e de Valorização dos Profissionais da Educação", entre "outras providências";
} 
Lei de Diretrizes e Bases da Educação que poderiam colocar por terra a Lei 10.639 .

Logo após a aprovação da reforma os boatos de que as leis $10.639^{7} \mathrm{e}$ $11.645^{8}$ haviam sido derrubadas pela reforma começam a se espalhar ${ }^{9}$, todos eles recheados de imprecisões ou erros, intencionais ou não.

Em seu texto de origem, protocolado no Congresso Nacional, a MP 746 previa alterações no Art. 26 da Lei $9.394\left(\operatorname{LDB}^{10}\right)$. A Lei 10.639 e depois a Lei 11.645, por sua vez, haviam promovido alterações fundamentais no Art. 26-A da LDB. O texto da MP 746 era substitutivo e dava margem para uma interpretação ambígua: ao apontar as alterações que passariam a vigorar no Art. 26, não ficava suficientemente legível para professores e militantes do movimento

\footnotetext{
${ }^{7}$ Lei que alterou a LDB e instituiu o ensino de História e Cultura Afro-brasileira nos ensinos fundamental e médio, nas redes pública e privada, e incluiu o 20 de Novembro, Dia Nacional da Consciência Negra, no calendário escolar;

${ }^{8}$ Lei que alterou a LDB, que já havia sido alterada pela Lei 10.639 , para agregar ao ensino de História e Cultura Afro-brasileira o ensino de História e Cultura Indígena;

${ }^{9}$ Uma das mensagens que circularam nas redes sociais e em aplicativos de mensagens instantâneas:

"Pessoal, as alterações na LDB saíram hoje!!! Da noite pro dia, só pra variar Publicada a nova legislação da educação, envolvendo o ensino médio e também mudanças no fundamental.

Não é mais obrigatório o ensino de cultura afrobrasileira.

Não é mais garantida a universalidade do ensino básico.

Não é mais garantida a gratuidade do ensino público básico (tanto no fundamental quanto no médio).

Não é mais obrigação do Estado garantir educação infantil para todos.

http://www.planalto.gov.br/ccivil_03/leis/L9394.htm

Está difícil de acreditar: http://www.planalto.gov.br/.../_Ato2015-.../2016/Mpv/mpv746.htm... No link da LDB indicado acima encontra-se no corpo do texto as alterações dessa MP.

Nesse novo formato eles anulam todos os parágrafos incluídos pelas leis 10.639 e 11.645.

Veja mais essa aberração do judiciário. Vamos denunciar.

O cúmulo será a aprovação da Nova LEI ORGÂNICA da Magistratura Nacional (LOMAN).

O projeto cria, por exemplo, auxílio-educação para filhos com até 24 anos de juízes, desembargadores e ministros do Judiciário em escolas e universidades privadas; auxílio-moradia equivalente a $20 \%$ do salário; transporte, quando não houver veículo oficial; reembolso por despesas médicas e odontológicas não cobertas por plano de saúde, e licenças para estudar no exterior com remuneração extra.

Se você repassar para somente dois amigos nas primeiras horas, em 28 horas toda população brasileira vai tomar conhecimento desse ABSURDO.

Não deixe de repassar, ao menos a 2 amigos; é o suficiente até gerar esta progressão de números."

(Grifo da mensagem)

${ }^{10}$ Lei de Diretrizes e Bases da Educação, de 20 de dezembro de 1996;
} 
negro se o "Art. 26" em questão correspondia apenas ao Art. 26 ou ao conjunto de artigos cujo "prefixo" era o número "26" (26 e 26-A).

Um outro fator gerador de confusões foram as mudanças que já haviam sido feitas pela Lei 11.645 no parágrafo 26-A. Ao incluir a história e a cultura indígena preservando todo o conteúdo anterior referente à história e cultura afro-brasileira da Lei 10.639 (2003) a Lei 11.645 (2008) inseriu um novo texto, substitutivo no parágrafo 26-A. Como o parágrafo na versão anterior passou a aparecer sobretaxado (riscado) no texto da lei, um olhar mais desatento (ou pouco acostumado aos trâmites legislativos) tendeu a avaliar erroneamente que a reforma havia de fato "derrubado" a Lei $10.639^{11}$.

\section{O Novo Ensino Médio: mais próximo do capital, mais distante da for- mação para as relações raciais e a cidadania}

Superada a polêmica sobre o suposto "fim" das leis 10.639/11.645, resta investigarmos em que medida a reforma poderá afetar o ensino de História e Cultura Africana (e Indígena) no Brasil.

\footnotetext{
${ }^{11}$ Redação do parágrafo 26-A da LDB após a Reforma do Ensino Médio:
}

Art. 26-A. Nos estabelecimentos de ensino fundamental e médio, oficiais e particulares, torna-se obrigatório o ensino sobre História e Cultura Afro-Brasileira. (Incluído pela Lei no 10.639, de 9.1.2003)

$\S 1^{\circ} \mathrm{O}$ conteúdo programático a que se refere o caput deste artigo incluirá o estudo da História da África e dos Africanos, a luta dos negros no Brasil, a cultura negra brasileira e o negro na formação da sociedade nacional, resgatando a contribuição do povo negro nas áreas social, econômica e política pertinentes à História do Brasil. (Incluído pela Lei no 10.639, de 9.1.2003)

$\S 2^{\circ}$ Os conteúdos referentes à História e Cultura Afro-Brasileira serão ministrados no âmbito de todo o currículo escolar, em especial nas áreas de Educação Artística e de Literatura e História Brasileiras. (Incluído pela Lei no 10.639, de 9.1.2003)

$\S 3^{\circ}$ (VETADO) (Incluído pela Lei no 10.639, de 9.1.2003)

Art. 26-A. Nos estabelecimentos de ensino fundamental e de ensino médio, públicos e privados, torna-se obrigatório o estudo da história e cultura afro-brasileira e indígena. (Redação dada pela Lei no 11.645, de 2008).

$\S 1^{\circ} \mathrm{O}$ conteúdo programático a que se refere este artigo incluirá diversos aspectos da história e da cultura que caracterizam a formação da população brasileira, a partir desses dois grupos étnicos, tais como o estudo da história da África e dos africanos, a luta dos negros e dos povos indígenas no Brasil, a cultura negra e indígena brasileira e o negro e o índio na formação da sociedade nacional, resgatando as suas contribuições nas áreas social, econômica e política, pertinentes à história do Brasil. (Redação dada pela Lei no 11.645, de 2008)

$\S 2^{\circ}$ Os conteúdos referentes à história e cultura afro-brasileira e dos povos indígenas brasileiros serão ministrados no âmbito de todo o currículo escolar, em especial nas áreas de educação artística e de literatura e história brasileiras. (Redação dada pela Lei no 11.645, de 2008). 
É praticamente um consenso entre especialistas que o ensino médio brasileiro alcança resultados ruins e possui altos índices de evasão escolar. Divergências aparecerão no momento em que se pensa a estratégia a ser adotada para lidar com estes dilemas. A depender de onde se quer chegar, seja a uma formação para a cidadania plena ou a uma formação mais direcionada para o mercado de trabalho, o remédio a ser aplicado via reforma pode variar.

Ao abrir caminho para a contratação de profissionais com "notório saber"12 para o preenchimento de postos de trabalho em escolas onde faltam professores com licenciatura, a reforma pode "abrir a porteira" para uma aproximação entre o mercado de trabalho e as escolas, com empresas direcionando o trabalho docente para seus interesses através da ampliação das formações "rápidas e práticas" para a atuação em sala de aula. Já existem empresas atuando desta forma no Brasil ${ }^{13} \mathrm{e}$ a tendência será de aprofundamento ${ }^{14}$. Este modelo de contratação via "notório saber" para cursos técnicos e profissionalizantes já é adotado no Sistema $\mathrm{S}^{15}$.

Que papel o ensino de História e Cultura Africana e Indígena terá num ambiente onde o currículo será cada vez mais pautado pelos interesses do mercado? Ao atrair quadros docentes de "notório saber" com bagagens mais práticas adquiridas no mercado de trabalho, em que medida teremos professores ainda mais despreparados para lidar com o conteúdo transversal das leis 10.639/11.645 em sala de aula? Não trata-se, portanto, de reivindicar reserva de mercado, mas sim de refletir sobre o perfil dos professores que a reforma pretende atrair e como a presença deles afetará ou não o ensino de História da África no ensino médio.

Outra mudança substancial que a reforma pauta é o aumento da carga horária. Educação integra ${ }^{16}$ pressupõe investimentos, uma vez que ela exige dedicação integral de professores, que devem estar na escola por mais tempo, além de gastos com alimentação dos alunos, para ficarmos apenas em dois exemplos práticos ${ }^{17}$. Não será exatamente uma surpresa se parcerias público privadas ${ }^{18}$ aparecerem no futuro como solução para a ampliação dos investi-

\footnotetext{
${ }^{12}$ Bacharéis sem licenciatura ou profissionais com experiência de trabalho em determinadas áreas;

13 A rede Ensina Brasil, por exemplo, que articula a Fundação Lemann, o Instituto Península, o Itaú Social, a Fundação Estudar e o Bain \& Company;

${ }^{14}$ PASSA PALAVRA, 2016;

${ }^{15}$ Sobre contratação via "notório saber", ver o Art. 6 da Lei 13.415;

${ }^{16}$ Sobre escola integral, ver o Art. 13 da Lei 13.415;

${ }_{17}$ Ver também Portaria Número 1.145, de 10 de outubro de 2016;

${ }^{18}$ Sobre as parcerias, ver parágrafos 6 e 8, do Art. 4 da Lei 13.415;
} 
mentos, uma vez que a reforma visa justamente estreitar a relação entre o en sino e o mundo produtivo. Lembremos também que estamos no contexto da PEC $55^{19}$, que congelou gastos sociais por 20 anos no Brasil. A reforma prevê formação técnica ou profissional via "vivência prática de trabalho no setor produtivo" ou em "ambientes de simulação", para os quais prevê justamente as famigeradas parcerias público privadas. Cabe mencionar aqui também o fato de a reforma ter sido pautada em perfeita sintonia com o $\mathrm{PL} 4330^{20}$, que estabelece terceirizações em atividades fim, ou seja, escolas poderão terceirizar suas aulas, com todas as consequências disto para os grandes capitalistas do setor (sistemas de ensino, sistemas de formação de professores e sistemas de oferecimento de materiais didáticos, entre outras possibilidades) ${ }^{21}$.

Num país marcado por movimentos de ocupação de escolas pautados por alunos, que demonstraram grande interesse e ampla capacidade de reformulação de grades, conteúdos e até mesmo inovações de gestão escolares, a reforma é também uma proposta que visa garantir aos alunos um pretenso protagonismo, apropriando-se de um anseio legítimo dos alunos por mudanças para adequar o ensino aos anseios do capital por uma força de trabalho mais produtiva. Os defensores da reforma repetiram à exaustão o objetivo de "tornar a escola mais atrativa e significativa para o aluno", com o jovem "traçando seu projeto de vida" através dos "itinerários formativos" ${ }^{22}$. Mas em que medida os itinerários formativos serão de fato escolhas pessoais dos alunos não pautadas pelas necessidades do mercado de trabalho se o eixo sistematizante da reforma cuida justamente de aproximar a escola dos interesses do capital?

As Lei 10.639 e 11.645 estipulam que "os conteúdos referentes à história e cultura afro-brasileira e dos povos indígenas brasileiros serão ministrados no âmbito de todo o currículo escolar", isto é, são conteúdos transversais. Se o ensino médio será repartido em itinerários formativos pela reforma, como fica a aplicação da transversalidade da Lei 10.639 na formação técnica e profissional?

\footnotetext{
${ }^{19}$ A Proposta de Emenda à Constituição 55, de 2016,a PEC do Teto dos Gastos Públicos, "alterou o ato das disposições constitucionais transitórias, para instituir o Novo Regime Fiscal, entre outras providências", congelando investimentos sociais por 20 anos;

${ }^{20}$ O Projeto de Lei 4330, do Deputado Sandro Mabel (PL/GO), apresentado em 26 de outubro de 2004, entre outras medidas, autoriza a terceirização nas atividades fins, a chamada terceirização total;

${ }^{21}$ PASSA PALAVRA, 2016;

${ }^{22}$ Sobre os itinerários formativos, ver o Art. 4 da Lei 13.415;
} 


\section{Conclusão: uma luta constante contra retrocessos}

Para que a Lei 10.639/03 não se torne "letra morta", é necessário um esforço constante de levantamento e balanço de sua implementação, sua aplicação prática e seus resultados. Nos dias 6 e 7 de novembro de 2007, por uma iniciativa da UNESCO e da Secretaria de Educação Continuada, Alfabetização e Diversidade do Ministério da Educação (MEC/Secad), uma oficina de trabalho em Brasília discutiu a implementação da Lei 10.639/03, elaborando um documento que um mês depois foi debatido em reunião com o Ministro Fernando Haddad $^{23}$. Nesta reunião foi indicada a instituição de um Grupo de Trabalho ${ }^{24}$ cujo foco foi "elaborar metas, propor estratégias e definir indicadores nacionais de implementação e acompanhamento da Lei 9.496/1996, alterada nos seus artigos 26-A e 79-B pela Lei 10.639/2003". Este grupo teria também a tarefa de "elaborar documento do Plano Nacional de Implementação e Acompanhamento da Lei 9.496/1996, alterada nos seus artigos 26-A e 79-B pela Lei $10.639 / 2003^{\prime \prime 25}$. Este esforço de acompanhamento e avaliação governamental foi descontinuado de 2016 para cá, o que torna o debate e a reflexão acadêmica sobre o tema ainda mais urgente e necessária.

Com o fim do ciclo de governos petistas após o golpe contra Dilma Roussef abre-se um período de resistência contra o desmonte das políticas que vinham sendo implementadas inaugurado pela Reforma do Ensino Médio. Outro retrocesso para a Educação Antirracista pode ser observado pelo exame comparativo entre a versão atual da Base Nacional Comum Curricular (BNCC de 2017) e as Diretrizes Curriculares Nacionais para a Educação das Relações Étnico-raciais e para o Ensino de História e Cultura Afro-brasileira e Africana. Em seu Trabalho de Conclusão de Curso, Karina Gonçalves Cardozo analisa esta terceira versão do texto da BNCC como uma proposição pautada pelo eurocentrismo, com a História da África ocupando um lugar periférico ${ }^{26}$. Esta abordagem da BNCC expressa em 2017 um esforço de retorno ao cenário pré-2003, um cenário onde a África e os africanos no Brasil eram tema de menor importância e suas contribuições para a formação do povo brasileiro eram minimizadas. A

\footnotetext{
${ }^{23}$ (MINISTÉRIO DA EDUCAÇÃO, 2008)

24 Portaria Interministerial MEC/MJ/Seppir n. 605, de 20 de maio de 2008 (in MINISTÉRIO DA EDUCAÇÃO, 2008)

${ }^{25}$ Diário Oficial da União, Seção 1, n. 96, p.12, 21 de maio de 2008 (in MINISTÉRIO DA EDUCAÇÃO, 2008)

${ }^{26}$ (CARDOZO, 2018)
} 
proposta do Novo Ensino Médio era apenas um primeiro passo para uma série de ações governamentais de desmonte que ainda viriam.

Em que pese o tamanho da tarefa de realizar um exercício de projeção de como a Reforma do Ensino Médio afetará o ensino de História da África frente a brevidade das linhas deste artigo, que servem no máximo como "pontapé inicial" para o debate, podemos desde já avaliar como negativo o saldo da reforma para a Lei 10.639, ainda que o tamanho do estrago só possa ser medido com maior profundidade futuramente, em estudos de mais fôlego e após implementação prática. Uma reforma construída às pressas com nítido interesse unilateral de agradar o capital, atendendo meros interesses do mercado de trabalho e focando em maior produtividade só poderia, como contrapartida, deixar de lado - quando não eliminar totalmente - questões relevantes para a formação cidadã dos brasileiros no ensino médio como a Lei 10.639 e o ensino de História e Cultura Afro-brasileira nas escolas.

\section{Referências}

BRASIL. Plano Nacional de Implementação das Diretrizes Curriculares Nacionais para a Educação das Relações Étnico-raciais e para o Ensino de História e Cultura Afro-Brasileira e Africana. Brasília: SECAD; SEPPIR, junho de 2009.LEI 9.394, de 20 de dezembro de 1996. Estabelece as diretrizes e bases da educação nacional. Disponível em: <http://planalto.gov.br/ccivil_03/LEIS/L9394.htm> Acesso em 3 de julho de 2018.

. LEI 10.639, de 9 de janeiro de 2003. Altera a Lei $\mathrm{n}^{0}$ 9.394, de 20 de dezembro de 1996, que estabelece as diretrizes e bases da educação nacional, para incluir no currículo oficial da Rede de Ensino a obrigatoriedade da temática "História e Cultura Afro-Brasileira", e dá outras providências. Disponível em: <http://www.planalto.gov.br/CCivil_03/leis/2003/L10.639.htm> Acesso em 3 de julho de 2018.

LEI 11.645, de 10 de março de 2008. Altera a Lei no 9.394, de 20 de dezembro de 1996, modificada pela Lei no 10.639, de 9 de janeiro de 2003, que estabelece as diretrizes e bases da educação nacional, para incluir no currículo oficial da rede de ensino a obrigatoriedade da temática "História e Cultura Afro-Brasileira e Indígena". Disponível em:

<http://planalto.gov.br/ccivil_03/_Ato2007-2010/2008/Lei/L11645.htm> Acesso em 3 de julho de 2018. 
BRASIL. LEI 13.415, de 16 de fevereiro de 2017. Altera as Leis nำs 9.394, de 20 de dezembro de 1996, que estabelece as diretrizes e bases da educação nacional, e 11.494, de 20 de junho 2007, que regulamenta o Fundo de Manutenção e Desenvolvimento da Educação Básica e de Valorização dos Profissionais da Educação, a Consolidação das Leis do Trabalho - CLT, aprovada pelo Decreto-Lei no 5.452, de 1 o de maio de 1943, e o Decreto-Lei $n=236$, de 28 de fevereiro de 1967; revoga a Lei no 11.161, de 5 de agosto de 2005; e institui a Política de Fomento à Implementação de Escolas de Ensino Médio em Tempo Integral. Disponível em: <http://pesquisa.in.gov.br/imprensa/jsp/visualiza/index.jsp? data $=17 / 02 / 2017 \&$ jornal=1\&pagina=1\&totalArquivos=440 $>$ Acesso em 11 de julho de 2018.

. MEDIDA PROVISÓRIA N 746, 23 de setembro de 2016. Institui a Política de Fomento à Implementação de Escolas de Ensino Médio em Tempo Integral, altera a Lei $n$ ㅇ 9.394, de 20 de dezembro de 1996, que estabelece as diretrizes e bases da educação nacional, e a Lei no 11.494 de 20 de junho 2007, que regulamenta o Fundo de Manutenção e Desenvolvimento da Educação Básica e de Valorização dos Profissionais da Educação, e dá outras providências. Disponível em: <http://pesquisa.in.gov.br/imprensa/jsp/visualiza/index.jsp?jornal=1000\&pagina=1\&data=23/09/2016> Acesso em 11 de julho de 2018.

. PORTARIA 1.145, de 10 de Outubro de 2016. Disponível em: <http:// pesquisa.in.gov.br/imprensa/jsp/visualiza/index.jsp? jornal=1\&pagina=23\&data=11/10/2016> Acesso em 24 de julho de 2018.

. PROJETO DE LEI 259, de 11 de Março de 1999. Dispõe sobre a obrigatoriedade da inclusão, no currículo oficial da Rede de Ensino, da temática "História e Cultura Afro-Brasileira" e dá outras providências. Câmara dos Deputados. Congresso Nacional. Dossiê do Projeto de Lei 259. Brasília, DF.

. PROJETO DE LEI 4.330, de 26 de outubro de 2004. Dispõe sobre o contrato de prestação de serviço a terceiros e as relações de trabalho deles decorrentes. Disponível em: <http://www.camara.gov.br/proposicoesWeb/ prop_mostrarintegra?codteor $=246979 \&$ filename $=P L+4330 / 2004>$ Acesso em 27 de julho de 2018.

. PROPOSTA DE EMENDA À CONSTITUIÇÃO 55, de 15 de dezembro de 2016. Altera o ato das disposições constitucionais transitórias, para instituir o Novo Regime Fiscal, e dá outras outras providências. Disponível em: <http:// 
www25.senado.leg.br/web/atividade/materias/-/materia/127337> Acesso em 28 de julho de 2018.

CARDOZO, K. G. Ensino de História e a História Cultural: Contemplação da Temática na Base Nacional Comum Curricular do Ensino Fundamental anos Finais. 2018. Trabalho de Conclusão de Curso. Curso de História, Instituto de Ciências Humanas, Universidade Federal de Pelotas, Pelotas-RS, 2018. Disponível em: <file://C:/Users/55199/Downloads/Karina-Cardozo-Vers\%C3\%A3o-Final.pdf> Acesso em 24 de julho de 2020.

CNTE. Análise da Medida Provisória 746, que Trata da Reforma do Ensino Médio. 2016. Disponível em <http://wwwavaliacaoeducacional.files.wordpress.com/2016/09/ensino_medio_analise_cnte.pdf> Acesso em 24 de julho de 2018.

DIEESE. Considerações sobre as Medidas Provisórias 664 e 665 de 30 de Dezembro de 2014. São Paulo: 2015. Disponível em: <http://www.dieese.org.br/ outraspublicacoes/2015/subsidiosConsideracoesMPs664665.pdf> Acesso em 18 de julho de 2018.

\section{MATSUKI, E. Alterações da LDB saíram hoje; é a nova legislação da educação} \#boato. Boatos.org, 22 de novembro de 2016. Disponível em: <http://www.boatos.org/politica/alteracoes-Idb-hoje-educacao.html> Acesso em 14 de julho de 2018.

MINISTÉRIO DA EDUCAÇÃO (MEC); ORGANIZAÇÃO DAS NAÇÕES UNIDAS PARA A EDUCAÇÃO, A CIÊNCIA E A CULTURA (UNESCO). Contribuições para Implementação da Lei 10.639/2003: Proposta de Plano Nacional de Implementação das Diretrizes Curriculares Nacionais da Educação das Relações Étnico-raciais e para o Ensino de História e Cultura Afro-Brasileira e Africana - Lei 10.639/2003. Novembro de 2008. Disponível em: <http://www.acordacultura.org.br/sites/ default/files/documentos/contribuicoes_para_implementacao_da_lei.pdf > Acesso em 21 de julho de 2020.

MINISTÉRIO DA EDUCAÇÃO (MEC). Base Nacional Comum Curricular, Terceira Versão. Brasília, 2016. Disponível em: <http://portal.mec.gov.br/index.php?option=com_docman\&view=download\&alias=78231-anexo-texto-bncc-reexportado-pdf-1\&category_slug=dezembro-2017-pdf\&ltemid=30192> Acesso em: 20 de julho de 2020. 
NERIS, N. A Voz e a Palavra do Movimento Negro na Constituinte de 1988. Belo Horizonte: Grupo Editorial Letramento, Selo Casa do Direito, 2018.

PASSA PALAVRA. Reforma do ensino médio: uma estratégia empresarial. 2016. Disponível em: <http://passapalavra.info/2016/10/109597> Acesso em 25 de julho de 2018.

PORTAL DA CONSTITUIÇÃO CIDADÃ. Sugestão 2.886 de Maio de 1987. Disponível em: <https://www2.camara.leg.br/atividade-legislativa/legislacao/Constituicoes_Brasileiras/constituicao-cidada/o-processo-constituinte/sugestoes-dosconstituintes> Acesso em 12 de julho de 2020. 